\title{
Changes in oestrogen-synthesizing ability of preovulatory bovine follicles relative to the peak of $\mathrm{LH}$
}

\author{
S. J. Dieleman and D. M. Blankenstein \\ Clinic for Veterinary Obstetrics, A.I. \& Reproduction, State University of Utrecht, Yalelaan 7 , \\ De Uithof, 3508 TD Utrecht, The Netherlands
}

\begin{abstract}
Summary. Preovulatory bovine follicles $(n=28)$ were collected at different times after the onset of standing oestrus until shortly before ovulation. In-vitro conversion of tritiated androstenedione in the presence of NADPH by homogenates of the follicular wall was compared in phases relative to the LH peak. During phase 0 (before the LH surge) conversion into oestradiol-17 $\beta$ was high and production of oestrone was about 8fold lower. During phases 1 (0-6 h after the LH peak) and $2 \mathrm{~A}(6-14 \mathrm{~h}$ after the $\mathrm{LH}$ peak) the production of oestradiol and oestrone remained constant; the percentage of remaining androstenedione increased. In phase $2 \mathrm{~B}$ (14-20 $\mathrm{h}$ after the $\mathrm{LH}$ peak) conversion into oestradiol and oestrone had decreased to about one third correlating with a higher percentage of remaining androstenedione. In phase 3 ( $20 \mathrm{~h}$ after the $\mathrm{LH}$ peak until ovulation) conversion into oestradiol and oestrone remained constant. The ratio between the production of oestrone and oestradiol remained constant throughout the phases of preovulatory development $(0 \cdot 13)$, indicating a concurrent inhibition of aromatase and 17 $\beta$-hydroxysteroid dehydrogenase activities. Conversion into 19 hydroxyandrostenedione showed a pattern similar to that of oestradiol, and testosterone was produced in minute quantities. The results indicate that in preovulatory bovine follicles eventual inhibition of aromatization takes place at about $14 \mathrm{~h}$ after the preovulatory LH peak.
\end{abstract}

\section{Introduction}

In general the preovulatory peak of luteinizing hormone $(\mathrm{LH})$ is believed to terminate oestradiol synthesis by preovulatory follicles (sheep: Moor, 1974; pig: Ainsworth, Tsang, Downey, Marcus \& Armstrong, 1980; cow: Staigmiller, England, Webb, Short \& Bellows, 1982). In the cow, the oestradiol concentration in the fluid of preovulatory follicles decreases about $6 \mathrm{~h}$ after the preovulatory LH peak (Dieleman, Kruip, Fontijne, de Jong \& van der Weyden, 1983b), and the androstenedione concentration in the follicular fluid falls sharply, coinciding with the LH peak (Dieleman, Bevers, Poortman \& van Tol, 1983a). This indicates that oestradiol synthesis in vivo is terminated by an immediate inhibitory action of the LH surge on androgen production, causing depletion of the aromatase substrate. However, inhibition of this enzyme complex appeared during phase 2 of the development of preovulatory follicles (Dieleman et al., 1983b), as indicated by the continuous increase of the ratio of oestrone and androstenedione concentrations in the follicular fluid until $14 \mathrm{~h}$ after the LH peak (Dieleman et al., 1983a).

In the present study, therefore, we investigated whether inhibition of the aromatizing activity does occur in the cow at about $14 \mathrm{~h}$ after the preovulatory LH peak.

\section{Materials and Methods}

Collection of follicles. The ovaries from normally cyclic Dutch-Friesian heifers $(\mathbf{N}=18)$ and cows $(\mathrm{N}=11)$ were collected at known times after the onset of oestrus until ovulation. The housing of the 
animals, assessment of the luteal function by estimating the progesterone concentration in the peripheral blood with a rapid radioimmunoassay (RIA) twice a day and detection of oestrus were as described previously (Dieleman et al., 1983b), as were recovery of the ovaries by ovariectomy, collection of blood samples and RIA of LH in plasma. Immediately after ovariectomy the ovaries were put on crushed ice. The diameters of the largest follicles present were measured with callipers; usually, the diameter of the second largest follicle was equal to or less than one-half of that of the largest follicle. The largest follicle, therefore, was considered to be the preovulatory follicle (Dufour, Whitmore, Ginther \& Casida, 1972); moreover, the second largest follicle was almost always atretic (S. J. Dieleman, unpublished data). The fluid of the preovulatory follicles was gently aspirated and small pieces of the follicular wall were fixed in Bouin's fluid and embedded in paraffin wax; sections of $7 \mu \mathrm{m}$ were stained with haematoxylin-eosin and periodic acid-Schiff's reagent. On the basis of histological examination the follicles (one per animal) used in this study were designated as non-atretic according to the criteria described by Kruip \& Dieleman (1982).

Chemicals. When not specified, chemicals were of analytical reagent grade and obtained from Merck AG, Darmstadt, West Germany; organic solvents were distilled just before use. [7(n)- $\left.{ }^{3} \mathrm{H}\right]$ Androstenedione (sp. act. $0.303 \mathrm{PBq} / \mathrm{mol}$ ) which was purified by thin-layer chromatography (t.l.c.), [4- ${ }^{14} \mathrm{C}$ ]androstenedione (sp. act. $1.96 \mathrm{TBq} / \mathrm{mol}$ ), $\left[4{ }^{-14} \mathrm{C}\right]$ testosterone (sp. act. $2 \cdot 15 \mathrm{TBq} / \mathrm{mol}$ ), [4$\left.{ }^{14} \mathrm{C}\right]$ oestrone (sp. act. $2.06 \mathrm{TBq} / \mathrm{mol}$ ) and $\left[4-{ }^{14} \mathrm{C}\right]$ oestradiol (sp. act. $2.04 \mathrm{TBq} / \mathrm{mol}$ ) were obtained from Amersham International Ltd, Bucks, U.K., and $\left[6,7-{ }^{3} \mathrm{H}\right] 19$-hydroxyandrostenedione (sp. act. 1.67 PBq/mol) from New England Nuclear, Boston, MA, U.S.A. The ${ }^{14} \mathrm{C}$-tracers were subjected to routine checks for purity by t.l.c. and, if necessary, purified by filtration on Sephadex LH-20 (Pharmacia Fine Chemicals, Uppsala, Sweden). Steroids were purchased from Makor Chemicals Ltd (Jerusalem, Israel) and Steraloids Inc. (Wilton, NH, U.S.A.). Aqueous samples for radioactivity measurements were dispersed in a xylene-based mixture and counted as described previously (Dieleman et al., 1983b). Samples in organic solvents were dissolved in Instafluor II (Packard Instruments Company, Downers Grove, IL, U.S.A.) and counted in a Tricarb counter (460 CD; Packard Instruments Company) and corrected for quenching by applying the external standard ratio method with four quench-correction curves.

Incubation. After excising the loosely embedded follicular wall from the ovary, the tissue was weighed and subsequently homogenized at $0^{\circ} \mathrm{C}$ in $13 \mathrm{ml}$ Tris- $\mathrm{HCl}$ buffer $(0 \cdot 1 \mathrm{M}, \mathrm{pH} 7 \cdot 4)$ with mannitol $(0.25 \mathrm{M})$. The mean interval from ovariectomy until homogenization was $22 \cdot 2 \pm 6.3$ (s.d.) $\min (n=29)$. The homogenates were centrifuged at $900 \mathrm{~g}$ for $20 \mathrm{~min}$ at $4^{\circ} \mathrm{C}$ and the supernatant was used for incubation. The incubation mixture consisted of $0.5 \mathrm{ml}$ propyleneglycol containing about $0.148 \mathrm{MBq}\left[7(\mathrm{n})-{ }^{3} \mathrm{H}\right]$ androstenedione and $3 \mathrm{ml}$ supernatant, to which was added $0.5 \mathrm{ml}$ of a solution of NADPH (Boehringer, Mannheim, West Germany) in Tris-HCl-mannitol buffer (final concentration of NADPH $0.2 \mathrm{mM}$ ). The incubations were carried out under continuous shaking at $39^{\circ} \mathrm{C}$ in an air atmosphere. After 30,60 and $120 \mathrm{~min}, 1 \mathrm{ml}$ samples were pipetted from the incubation mixture and the enzyme reactions were stopped by the addition of $3 \mathrm{ml}$ dichloromethane; thereafter the fractions were stored at $-25^{\circ} \mathrm{C}$. Blank incubations with $3 \mathrm{ml}$ Tris- $\mathrm{HCl}-$ mannitol buffer instead of homogenate showed no conversion of androstenedione after 30,60 and 120 min incubation $(n=4)$ respectively.

Extraction and processing. After 4-fold extraction with dichloromethane (recovery $98 \cdot 28 \pm$ $0.59 \%, n=87$ ), a mixture of ${ }^{14} \mathrm{C}$-labelled steroids (androstenedione, testosterone, oestrone and oestradiol, about $1.8,0.8,0.9$ and $5.0 \mathrm{kBq}$ respectively) was added in a known proportion in $10 \mu \mathrm{l}$ for recovery and recrystallization purposes. Subsequently, the residues after evaporation under $\mathrm{N}_{2}$ were subjected to filtration on Sephadex LH-20 (6.0 g in a reusable glass column, i.d. $9 \mathrm{~mm})$ eluted with benzene (Uvasol; Merck AG) :dichloromethane : methanol $(60: 35: 5$, by vol.), after which the fractions containing androstenedione, oestrone and oestradiol were further purified by recrystallization up to a constant ratio of ${ }^{3} \mathrm{H} /{ }^{14} \mathrm{C}$ activities. The fraction containing testosterone 
and 19-hydroxylated androgens was purified by column chromatography (c.l.c.) on Celite 545 (Serva Feinbiochemica, Heidelberg, West Germany) as described by Van Landeghem et al. (1981); the columns were developed with a discontinuous gradient of ethylacetate in $i s o$-octane $(1-100 \%$, $\mathrm{v} / \mathrm{v}$ ). To the respective Celite fractions, $50 \mu \mathrm{g}$ reference testosterone, 19-hydroxyandrostenedione and 19-hydroxytestosterone were added. The testosterone fraction was acetylated $\left(1 \mathrm{~h}\right.$ at $60^{\circ} \mathrm{C}$ in a closed reaction vial) by dissolving it in $100 \mu \mathrm{l}$ dry pyridine to which was added $200 \mu \mathrm{l}$ acetic anhydride. The three steroid fractions were further purified by t.l.c. (dichloromethane :methanol, $97: 3, v / v)$. Conversion percentages of oestrone and oestradiol, and the percentage of androstenedione remaining, were calculated from the ${ }^{3} \mathrm{H}$ activity of the pure steroids in proportion to the total ${ }^{3} \mathrm{H}$ activity after extraction and corrected for recovery. Those of testosterone were estimated by correcting the ${ }^{3} \mathrm{H}$ activity of the testosterone-acetate fraction after t.l.c. for recovery and the relative purity (the proportion of ${ }^{3} \mathrm{H}$ activity of the steroid after and before recrystallization; $74 \cdot 1 \pm$ $18 \cdot 2 \%, n=15$ ). Conversion into 19 -hydroxyandrostenedione was calculated by correcting the ${ }^{3} \mathbf{H}$ activity after t.l.c. for the mean recovery $(60 \cdot 5 \pm 12.9 \%, n=7)$ as determined by performing the purification procedure with the $6,7-{ }^{3} \mathrm{H}$-labelled product, and for the relative purity $(94 \cdot 1 \pm 2 \cdot 7 \%, n$ $=15$ ). The coefficient of variation due to statistical errors in measurements of radioactivity was $<4$ and $<15 \%$ for percentage conversions of $>1$ and $<0.5$ respectively.

Statistical analysis. The paired $t$ test (two-tailed) was used to compare the means of two samples. Differences between the means of samples in grouped data were tested for significance by analysis of variance according to Scheffé (1959).

\section{Results}

The time when the maximum LH level was recorded in peripheral blood was defined as the LH peak. For animals kept in circumstances similar to those in this study, the mean \pm s.d. intervals between the onset of oestrus, i.e. first standing oestrus, and the onset of the LH surge (first elevated concentration of $\mathrm{LH}$ followed by higher values) and between the maximum $\mathrm{LH}$ value and ovulation, have been reported previously to be $1.73 \pm 2.35 \mathrm{~h}$ and $24 \pm 1.4 \mathrm{~h}$ respectively (Dieleman et al., 1983b).

Before the LH surge (phase 0 ) 8 follicles were collected; the mean ( \pm s.e.m.) diameter and weight of the follicular wall were $17.9 \pm 0.9 \mathrm{~mm}$ and $345 \pm 40 \mathrm{mg}$ respectively. After the LH peak 20 follicles were collected : 5 at $0-6 \mathrm{~h}$ after the LH peak (phase 1; size and weight : $16.8 \pm 0.9 \mathrm{~mm}$ and $284 \pm 40 \mathrm{mg}$ respectively), 6 at $6-14 \mathrm{~h}$ (phase $2 \mathrm{~A} ; 17.0 \pm 0.8 \mathrm{~mm}, 353 \pm 48 \mathrm{mg}$ ), $5 \mathrm{at} 14-20 \mathrm{~h}$ (phase $2 \mathrm{~B} ; 18.3 \pm 0.6 \mathrm{~mm}, 380 \pm 30 \mathrm{mg}$ ) and 4 between $20 \mathrm{~h}$ and ovulation (phase $3 ; 18.5 \pm 0.9$ $\mathrm{mm}, 486 \pm 22 \mathrm{mg})$. In one heifer $(16 \mathrm{~mm}, 209 \mathrm{mg})$ ovulation had taken place shortly before ovariectomy, and the interval after the LH peak was $23 \mathrm{~h}$. There was no difference in size or weight of the wall of follicles originating from heifers or cows, and the diameter varied from 15 to $22 \mathrm{~mm}$ independently of the stage of preovulatory development. Analysis of variance proved the apparent increase in weight of the follicular wall to be non-significant.

\section{Conversion of $\left[7(n)-{ }^{3} H\right]$ androstenedione into oestradiol, oestrone and intermediary steroids}

Text-figure 1 shows the mean conversion percentage of oestradiol-17 $\beta$ and the percentage of remaining androstenedione after incubation of homogenates of preovulatory follicles in the phases between the onset of oestrus and ovulation with the results of the statistical analysis. The apparently lower conversion percentage of oestradiol $0-14 \mathrm{~h}$ after the LH peak was not significantly different from that before the $\mathrm{LH}$ peak, except after $60 \mathrm{~min}$ incubation. After $14 \mathrm{~h}$ the conversion percentage of oestradiol had decreased sharply and remained low until ovulation. After 30,60 and $120 \mathrm{~min}$ incubation the pattern of the percentage of remaining androstenedione (Text- 


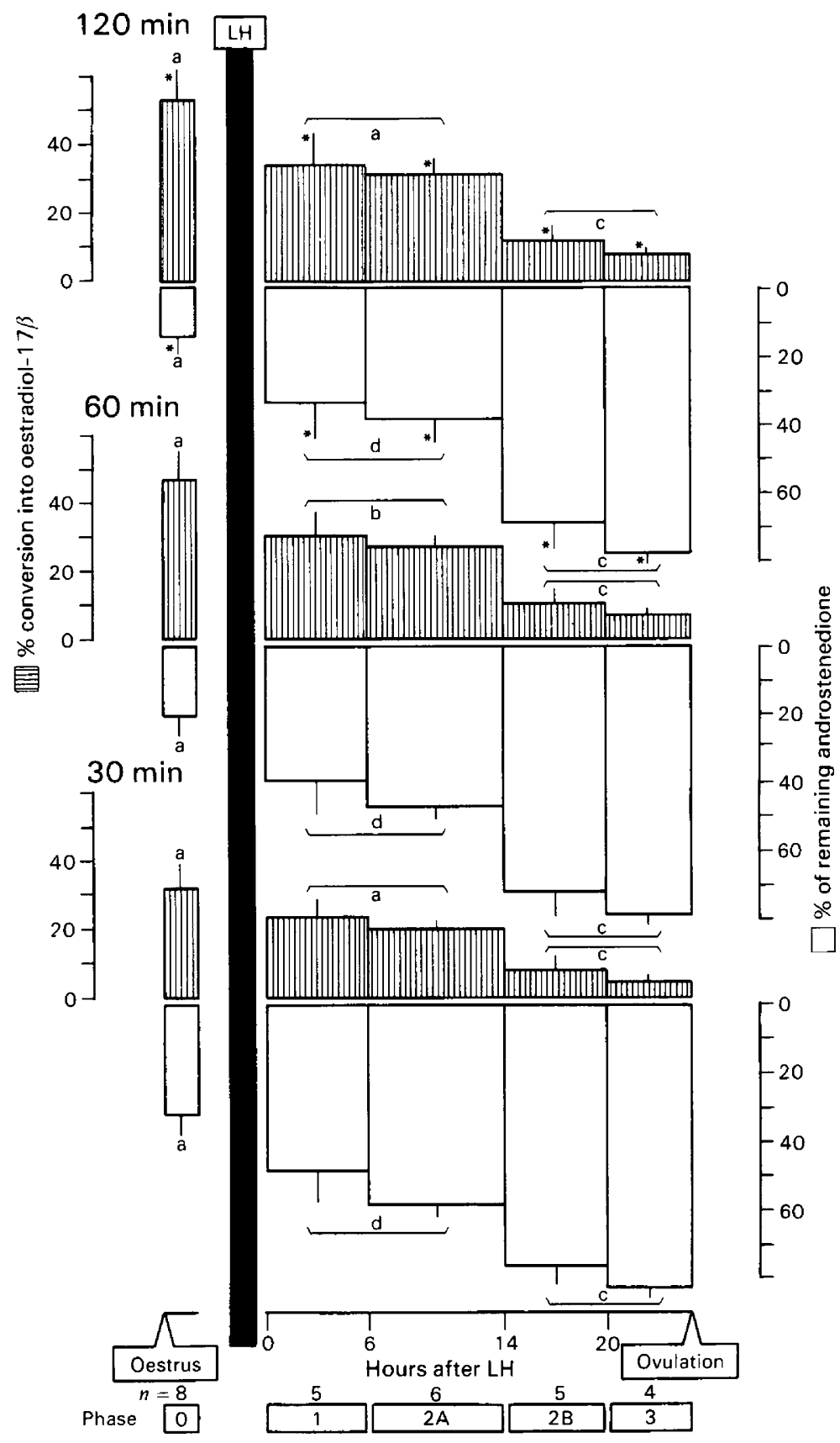

Text-fig. 1. Conversion percentage of oestradiol- $17 \beta$ and the percentage of remaining androstenedione after incubation for 30,60 and 120 min with $\left.[7(\mathrm{n}))^{3} \mathrm{H}\right]$ androstenedione of homogenates of preovulatory bovine follicles in the phases between onset of oestrus and ovulation. Values are mean \pm s.e.m. for the no. of follicles indicated $(n)$. At each incubation time and hormone, values with a different superscript letter are significantly different $(P<$ $0.05)$. ${ }^{*}$ Values significantly different from those after incubation for $30 \mathrm{~min}(P<0.05)$. 
fig. 1) showed three significantly different periods: before the LH surge; from 0 to $14 \mathrm{~h}$ after the LH peak; from $14 \mathrm{~h}$ until ovulation. The increase of the production of oestrone (Table 1) during incubation was significant at phases 0 and $2 \mathrm{~A}(P<0.01$ for both). The relative pattern of the conversion percentage of oestrone after incubation for 30,60 and 120 min was similar to that of oestradiol in the phases between onset of oestrus and ovulation. The pattern of the sum of the conversion percentages of oestradiol and oestrone was similar to that of oestradiol; statistical analysis of these sums produced the same significant differences as observed for oestradiol. Analysis of variance of the ratios between the conversion percentages of oestrone and those of oestradiol in the phases between onset of oestrus and ovulation showed no significant differences; it remained constant also during incubation (overall mean: $0 \cdot 130 \pm 0.005, n=84$ ).

The one follicle collected shortly after ovulation showed a low conversion percentage of oestradiol after incubation for 30,60 and $120 \mathrm{~min}(0.56,1.00$ and $1.51 \%$ respectively) and conversion into oestrone was near the detection limit, i.e. $<0 \cdot 1 \%$.

The production of intermediary steroids is summarized in Table 2 . The relative pattern of the conversion into 19-hydroxyandrostenedione was similar to that of oestradiol in the phases between onset of oestrus and ovulation. Shortly before ovulation (phase 3 ) the production of testosterone was higher $(P<0.05)$ than before the LH surge (phase 0 ). The unidentified steroid fraction mainly showed a mobility on Sephadex LH-20 similar to that of 19-aldehydo-androstenedione, and the presence of 19-hydroxytestosterone could not be demonstrated.

Table 1. Conversion percentage of oestrone after incubation with $\left[7(\mathrm{n})-^{3} \mathrm{H}\right]$ androstenedione of homogenates of preovulatory bovine follicles in the phases between onset of oestrus and ovulation

\begin{tabular}{|c|c|c|c|c|c|}
\hline \multirow[b]{2}{*}{ Phase } & \multirow{2}{*}{$\begin{array}{l}\text { Period* } \\
\text { (h) }\end{array}$} & \multirow{2}{*}{$\begin{array}{l}\text { No. of } \\
\text { follicles }\end{array}$} & \multicolumn{3}{|c|}{ Incubation time ( $\mathrm{min}$ ) } \\
\hline & & & 30 & 60 & 120 \\
\hline 0 & Before & 8 & $4.02 \pm 0.56^{\mathrm{a}}$ & $5.31 \pm 0.61^{\mathrm{a}}$ & $6.82 \pm 0.57^{a}$ \\
\hline 1 & $0-6$ & 5 & $2.74 \pm 0.59\}_{b}$ & $3.62 \pm 0.78 乙_{d}$ & $4.92 \pm 1.25\}$ \\
\hline $2 \mathrm{~A}$ & $6-14$ & 6 & $2.13 \pm 0.32\}^{b}$ & $3.16 \pm 0.48\}^{0}$ & $4.52+0.72\}$ \\
\hline 2B & $14-20$ & 5 & $0.92 \pm 0.28\}$ & $1.19 \pm 0.40\} \mathrm{c}$ & $1.53 \pm 0.61\}$ \\
\hline 3 & $20-25$ & 4 & $0.71 \pm 0.13\}^{c}$ & $0.81 \pm 0.11\}^{c}$ & $1.01 \pm 0.19\}$ \\
\hline
\end{tabular}

Values are mean \pm s.e.m.

* In relation to $\mathbf{L} \bar{H}$ peak level.

Values in columns with different superscript letters are significantly different (ac: $P<0.001 ; a b, a d, b c$ : $P<0.05 ; \mathrm{dc}: P<0.005)$.

Table 2. Conversion percentages of 19-hydroxyandrostenedione and testosterone, and the percentage of unidentified steroid after incubation for $120 \mathrm{~min}$ with $\left[7(\mathrm{n})-{ }^{3} \mathrm{H}\right]$ androstenedione of homogenates of preovulatory bovine follicles in the phases between onset of oestrus and ovulation

\begin{tabular}{lccccc}
\hline Phase & $\begin{array}{c}\text { Period* } \\
\text { (h) }\end{array}$ & $\begin{array}{c}\text { No. of } \\
\text { follicles }\end{array}$ & $\begin{array}{c}\text { 19-Hydroxy- } \\
\text { androstenedione }\end{array}$ & Testosterone & Unidentified \\
\hline 0 & Before & 8 & $10 \cdot 3 \pm 3 \cdot 7$ & $0 \cdot 25 \pm 0 \cdot 09$ & $15 \cdot 1 \pm 2 \cdot 0$ \\
I & $0-6$ & 5 & $13 \cdot 9 \pm 5 \cdot 3$ & $0 \cdot 32 \pm 0 \cdot 10$ & $13 \cdot 2 \pm 2 \cdot 1$ \\
$2 \mathrm{~A}$ & $6-14$ & 6 & $10 \cdot 4 \pm 4 \cdot 7$ & $0 \cdot 59 \pm 0 \cdot 09$ & $14 \cdot 1 \pm 2 \cdot 6$ \\
$2 \mathrm{~B}$ & $14-20$ & 5 & $7 \cdot 5 \pm 1 \cdot 8$ & $0 \cdot 68 \pm 0 \cdot 15$ & $9 \cdot 6 \pm 0 \cdot 6$ \\
3 & $20-25$ & 4 & $4 \cdot 3 \pm 0.9$ & $0 \cdot 86 \pm 0 \cdot 23$ & $8 \cdot 1 \pm 0.4$ \\
\hline
\end{tabular}




\section{Discussion}

Changes in aromatizing ability of preovulatory bovine follicles relative to the preovulatory peak of LH were investigated in an in-vitro system using homogenates of the follicular wall, with tritiated androstenedione as precursor since this steroid is the final androgen produced by the theca interna (Lacroix, Eechaute \& Leusen, 1974). Although in this way the in-vivo intercellular contact and intracellular organization are lost, this system does provide quantitative data on the aromatizing ability of the follicles. Separate incubation of granulosa cells may produce variable results, since collection of these cells is seldom quantitative as shown by histological examination of the remaining theca interna (see Ireland \& Roche, 1982). The mural granulosa cells adjacent to the basement membrane are particularly liable to remain attached to the theca interna, and these cells may have the highest capacity for aromatization (Hillier, 1981). Moreover, using homogenates of the follicular wall avoided possible deprivation of unknown thecal factors affecting granulosa aromatase activity as suggested by the in-vitro experiments of Lacroix et al. (1974) with separated and recombined bovine thecal and granulosa cells. Assuming that the concentrations of steroids in the wall of preovulatory bovine follicles are similar to those in the fluid, as in sheep (Murdoch \& Dunn, 1982), the concentration of tritiated androstenedione $(0 \cdot 122 \mu \mathrm{mol} / \mathrm{l})$ used in the present incubation experiments was about 4-fold higher than the concentration of endogenous androstenedione of the wall of the preovulatory follicles before the LH surge (phase 0 ); its concentration in the fluid of preovulatory bovine follicles during this phase is $1.4 \mu \mathrm{mol} / 1$ (Dieleman et al., 1983a), which would give an androstenedione concentration of $0.028 \mu \mathrm{mol} / 1$ after correction for the concentration of homogenate during incubation. Hillier, Reichert \& Van Hall (1981) showed that the androgen concentration in the fluid of human preovulatory follicles is sufficient to permit maximal aromatase activity of the granulosa cells in vitro. Although thecal cells are capable of androgen synthesis in vitro without exogenous substrate (pig: Evans, Dobias, King \& Armstrong, 1981), endogenous androstenedione production during the present experiments probably did not interfere with the production of tritiated oestrogens, because this production remained constant throughout the period 0 to $14 \mathrm{~h}$ after the LH peak, whereas a sharp decrease to one seventh of the androstenedione concentration in the fluid has been observed in follicles during phase $1(0-6 \mathrm{~h}$ after the LH peak: Dieleman et al., 1983a). It is therefore assumed that the sum of the oestradiol and oestrone production in the in-vitro system used reflected the in-vivo changes of the aromatizing ability of the preovulatory follicles.

The high conversion into oestrogens and their production ratio before the LH surge are in accordance with the high oestradiol concentration and the ratio between the concentrations of the two steroids in the fluid of follicles at phase 0 respectively (Dieleman et al., 1983a, b). From 0 to $14 \mathrm{~h}$ after the LH peak (phases 1 plus $2 \mathrm{~A}$ ) the aromatizing ability remained constant at a lower level (not significant) than in the preceding phase before the LH surge, but conversion into oestrone was lower and the percentage of remaining androstenedione higher than in phase 0 . This may be due to the possible difference in aromatizing capacity of the mural granulosa cells and those bordering the antrum, and to the lag between the times at which $\mathrm{LH}$ reaches these cells. Passage of LH from the thecal blood capillaries through the avascular membrana granulosa to the antrum takes about $4 \mathrm{~h}$ as indicated by the LH peak in the follicular fluid at $4 \mathrm{~h}$ after the peak in the peripheral blood (Dieleman et al., 1983a). Also the aromatase activity may be affected by changes in thecal cell function as indicated by the elevated progesterone concentration and the sharp decline of the androstenedione concentration in the follicular fluid during phase 1 (Dieleman et al., 1983a, b). Saidapur \& Greenwald (1979) showed that progesterone administered in vivo depresses the oestradiol concentration in the peripheral blood of hamsters. In the cow, in phase $2 \mathrm{~B}(14-20 \mathrm{~h}$ after the LH peak) the aromatizing ability had decreased to about one third of that in the preceding phases 1 and $2 \mathrm{~A}$. Thereafter in phase 3 it decreased further until ovulation. The one follicle collected shortly after ovulation showed a still lower aromatizing ability, and histological examination of this structure revealed an intact membrana granulosa with a luteinized appearance similar to that of preovulatory follicles at phase 3 (Dieleman et al., 1983b). This is in accordance 
with the findings of Henderson \& Moon (1979) that bovine granulosa cells show a marked loss of aromatizing ability during luteinization in culture.

The similarity between the pattern of the conversion percentage of 19-hydroxyandrostenedione and those of the oestrogens, the low testosterone production and the absence of detectable 19hydroxytestosterone suggest that androstenedione serves as major substrate for aromatase, since the first of the three hydroxylations during aromatization occurs at C-19 (Thompson \& Siiteri, 1974). Addition of testosterone to the medium of cultured bovine follicles at oestrus did not enhance oestradiol secretion by these follicles (Staigmiller et al., 1982). The finding that the ratio of the conversion percentages of oestrone and oestradiol remained constant throughout the phases of preovulatory development may indicate that the activities of $17 \beta$-hydroxysteroid dehydrogenase (17 $\beta-$ HSD) and aromatase are inhibited simultaneously. On the other hand, 17 $\beta-H S D$ activity may be limited due to a decrease of substrate, although this seems less likely, since conversion into testosterone remained low even when androstenedione was available to a greater extent as substrate for 17\%-HSD.

The observed pattern of aromatizing ability demonstrated that eventual inhibition of the aromatizing enzyme system takes place in preovulatory bovine follicles at about $14 \mathrm{~h}$ after the preovulatory LH peak. This confirms the concept based on changes in vivo in the ratio between the concentrations of oestrone and androstenedione in the fluid of preovulatory bovine follicles (Dieleman et al., 1983a). Furthermore, these findings are consistent with the reported lower aromatizing ability of bovine granulosa cells collected $10-15 \mathrm{~h}$ after the LH peak than of cells before the LH peak (Fortune \& Hansel, 1979). Oestradiol production by preovulatory bovine follicles in vivo is probably terminated by an immediate inhibitory action of LH on thecal androstenedione production (Dieleman et al., 1983a), but the effect on the activity of the aromatizing enzyme system takes about $10 \mathrm{~h}$ to become evident. It may be assumed that the granulosa $\mathrm{LH}$ receptors are saturated at $4 \mathrm{~h}$ after the $\mathrm{LH}$ peak in the peripheral blood (Dieleman $e t$ al., 1983a); Ireland \& Roche (1982) reported a 5-fold lower binding capacity for hCG of bovine granulosa cells collected after than before the LH surge. Whether the preovulatory LH peak inhibits aromatization by a direct or indirect action on the aromatizing enzyme systems needs further investigation. Suzuki \& Tamaoki (1983) reported an acute decrease of cytochrome P-450 in rat preovulatory ovaries after treatment with hCG, but the activity of NADPH-cytochrome c reductase was not significantly impaired.

Four phases of preovulatory development can be distinguished with regard to changes in the steroidal microenvironment of the bovine oocyte (Dieleman et al., 1983b) which is considered to be mature at phase 3 (Kruip, Cran, Van Beneden \& Dieleman, 1983). The results of this study show that one phase (phase 2) can be subdivided according to the eventual inhibition of aromatase.

We thank Professor A. H. Willemse, Professor P. A. Voogt, Dr M. M. Bevers and Dr H. J. N. Schoenmakers for reading the manuscript; Dr P. Fontijne and Dr G. C. van der Weyden and assistants for the surgery; Mrs H. T. M. van Tol and Mr A. V. P. van de Poll for round-the-clock assistance with detection of oestrus and sampling: Mr S. H. J. Mook and co-workers for tending the animals; and $\mathrm{Mr} \mathrm{W}$. Bes for drawing the figure.

\section{References}

Ainsworth, L., Tsang, B.K., Downey, B.R., Marcus, G.J. \& Armstrong, D.T. (1980) Interrelationships between follicular fluid steroid levels, gonadotropic stimuli, and oocyte maturation during preovulatory development of porcine follicles. Biol. Reprod. 23, 621-627.
Dieleman, S.J., Bevers, M.M., Poortman, J. \& van Tol, H.T.M. (1983a) Steroid and pituitary hormone concentrations in the fluid of preovulatory bovine follicles relative to the peak of $\mathrm{LH}$ in the peripheral blood. J. Reprod. Fert. 69, 641-649. 
Dieleman, S.J., Kruip, Th.A.M., Fontijne, P., de Jong, W.H.R. \& van der Weyden, G.C. (1983b) Changes in oestradiol, progesterone and testosterone concentrations in follicular fluid and in the micromorphology of preovulatory bovine follicles relative to the peak of luteinizing hormone. $J$. Endocr. 97, 3142.

Dufour, J., Whitmore, H.L., Ginther, O.J. \& Casida, L.E. (1972) Identification of the ovulating follicle by its size on different days of the estrous cycle in heifers. $J$. Anim. Sci. 34, 85-87.

Evans, G., Dobias, M., King, G.J. \& Armstrong, D.T. (1981) Estrogen, androgen, and progesterone biosynthesis by theca and granulosa of preovulatory follicles in the pig. Biol. Reprod. 25, 673-682.

Fortune, J.E. \& Hansel, W. (1979) Effects of the LH surge on steroid secretion by theca and granulosa cells of bovine preovulatory follicles. Biol. Reprod. 20, Suppl. 1, 46, Abstr.

Henderson, K.M. \& Moon, Y.S. (1979) Luteinization of bovine granulosa cells and corpus luteum formation associated with loss of androgen-aromatizing ability. J. Reprod. Fert. 56, 89-97.

Hillier, S.G. (1981) Regulation of follicular oestrogen biosynthesis: a survey of current concepts. $J$. Endocr. 89, $3 P-18 P$.

Hillier, S.G., Reichert, L.E., Jr \& Van Hall, E.V. (1981) Control of preovulatory follicular estrogen biosynthesis in the human ovary. J. clin. Endocr. Metab. 52, $847-856$.

Ireland, J.J. \& Roche, J.F. (1982) Development of antral follicles in cattle after prostaglandin-induced luteolysis: changes in serum hormones, steroids in follicular fluid, and gonadotropin receptors. Endocrinology 111, 2077-2086.

Kruip, Th.A.M. \& Dieleman, S.J. (1982) Macroscopic classification of bovine follicles and its validation by micromorphological and steroid biochemical procedures. Reprod. Nutr. Dévelop. 22, 465-473.
Kruip, Th.A.M., Cran, D.G., Van Beneden, Th.H. \& Dieleman, S.J. (1983) Structural changes in bovine oocytes during final maturation in vivo. Gamete Res. 8, 29-47.

Lacroix, E., Eechaute, W. \& Leusen, I. (1974) The biosynthesis of estrogens by cow follicles. Steroids 23, 337-356.

Moor, R.M. (1974) The ovarian follicle of the sheep: inhibition of oestrogen secretion by luteinizing hormone. J. Endocr. 61, 455-463.

Murdoch, W.J. \& Dunn, T.G. (1982) Alterations in follicular steroid hormones during the preovulatory period in the ewe. Biol. Reprod. 27, 300-307.

Saidapur, S.K. \& Greenwald, G.S. (1979) Regulation of $17 \beta$-estradiol synthesis in the proestrous hamster: role of progesterone and luteinizing hormone. Endocrinology 105, 1432-1439.

Scheffé, H. (1959) The Analysis of Variance. John Wiley, New York.

Staigmiller, R.B., England, B.G., Webb, R., Short, R.E. \& Bellows, R.A. (1982) Estrogen secretion and gonadotropin binding by individual bovine follicles during estrus. J. Anim. Sci. 55, 1473-1482.

Suzuki, K. \& Tamaoki, B. (1983) Acute decrease by human chorionic gonadotropin of the activity of preovulatory ovarian $17 \alpha$-hydroxylase and C-17-C-20 lyase is due to decrease of microsomal cytochrome $\mathbf{P}$ 450 through de novo synthesis of ribonucleic acid and protein. Endocrinology 113, 1985-1991.

Thompson, E.A. \& Siiteri, P.K. (1974) Utilization of oxygen and reduced nicotinamide adenine dinucleotide phosphate by human placental microsomes during aromatization of androstenedione. J. biol. Chem. 249, 5364-5372.

Van Landeghem, A.A.J., Poortman, J., Deshpande, N., Di Martino, L., Tarquini, A., Thijssen, J.H.H. \& Schwarz, F. (1981) Plasma concentration gradient of steroid hormones across human mammary tumours in vivo. J. Steroid Biochem. 14, 741-747.

Received 19 March 1984 